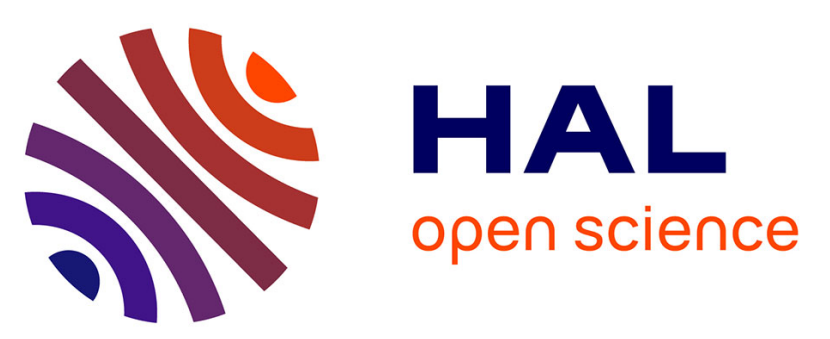

\title{
Determination of Defect Densities in Thin (i) a-Si:H Used as the Passivation Layer in a-Si:H/c-Si Heterojunction Solar Cells from Static Planar Conductance Measurements
}

\author{
Alexandra Levtchenko, Sylvain Le Gall, Rudolf Brüggemann, Jean-Paul
} Kleider

\section{To cite this version:}

Alexandra Levtchenko, Sylvain Le Gall, Rudolf Brüggemann, Jean-Paul Kleider. Determination of Defect Densities in Thin (i) a-Si:H Used as the Passivation Layer in a-Si:H/c-Si Heterojunction Solar Cells from Static Planar Conductance Measurements. physica status solidi (RRL) - Rapid Research Letters, 2019, 13 (12), pp.1900411. 10.1002/pssr.201900411 . hal-02301811

\section{HAL Id: hal-02301811 https://hal.science/hal-02301811}

Submitted on 19 Dec 2019

HAL is a multi-disciplinary open access archive for the deposit and dissemination of scientific research documents, whether they are published or not. The documents may come from teaching and research institutions in France or abroad, or from public or private research centers.
L'archive ouverte pluridisciplinaire $\mathbf{H A L}$, est destinée au dépôt et à la diffusion de documents scientifiques de niveau recherche, publiés ou non, émanant des établissements d'enseignement et de recherche français ou étrangers, des laboratoires publics ou privés. 


\title{
Determination of the Defect Density in Thin (i) a-Si:H Used as Passivation Layer in a-Si:H/c-Si Heterojunction Solar Cells from Static Planar Conductance Measurements
}

\author{
Alexandra Levtchenko, Sylvain Le Gall*, Rudolf Brüggemann, Jean-Paul Kleider \\ GeePs, UMR 8507, CNRS, CentraleSupélec, Université Paris-Sud, Université Paris-Saclay, \\ Sorbonne Université, 11 rue Joliot-Curie, Plateau de Moulon, F-91192 Gif-sur-Yvette Cedex, \\ France \\ *E-mail : sylvain.le-gall@geeps.centralesupelec.fr
}

Keywords: a-Si:H/c-Si heterojunction, passivating layer, dangling bonds, coplanar conductance, electrical modeling

A set of (p) a-Si:H / (i) a-Si:H / (n) c-Si heterostructures has been investigated by coplanar conductance measurements. The thickness of the (i) a-Si:H buffer layer is varied between 2 and $50 \mathrm{~nm}$, well beyond the values used in heterojunction solar cells. The change in this thickness plays a role on band bending at the heterointerface and therefore impacts the level of inversion of carrier population at the c-Si surface. Measurements have been compared to $1 \mathrm{D}$ analytical calculations and to 2D electrical modeling. It is demonstrated that the deep defect density, related to silicon dangling bonds, in the (i) a-Si:H layer is strongly increasing from $1 \times 10^{17}$ to $4 \times 10^{18} \mathrm{~cm}^{-3}$ when the (i) a-Si:H layer thickness is decreased from 50 to $2 \mathrm{~nm}$. This result is interpreted in terms of defect formation and dependence of the defect density upon the position of the Fermi level with respect to the valence band edge. Quantitative analysis in the framework of the defect-pool model demonstrates that the strong increase of defect density is also promoted by an increase of the width of the valence band tail in the thin (i) a-Si:H layer, suggesting that a very thin layer also suffers from increased disorder. 


\section{Introduction}

Solar cells using amorphous silicon/crystalline silicon heterojunctions with interdigitated back contacts hold the world record efficiency of silicon-based photovoltaic energy conversion. ${ }^{[1,2]}$ The use of undoped hydrogenated amorphous, called intrinsic and denoted (i) a-Si:H, as a buffer layer between the doped hydrogenated amorphous silicon (a-Si:H) layer and the crystalline silicon (c-Si) wafer in this solar cell is known to provide excellent passivation of the c-Si surface. This improved passivation is generally attributed to low defect density at the (i) a$\mathrm{Si}: \mathrm{H} / \mathrm{c}-\mathrm{Si}$ interface related to lower defect density in (i) a-Si:H as compared to doped a-Si:H. ${ }^{[3]}$ However, the defect density in the buffer (i) a-Si:H layer and the (i) a-Si:H / (c)-Si interface state density could never be directly measured in solar cell structures. The quality of the interface is assessed at the cell level from the photovoltaic performance of the solar cell or at an earlier step of cell fabrication from the effective lifetime on cell precursors consisting of the c-Si wafers with the a-Si:H layers deposited on both faces. ${ }^{[4-15]}$ Both the photovoltaic performance and the effective lifetime are related to the dynamics and recombination of photogenerated carriers, which do not depend only on the density of defects but also on their degree of occupation and on their capture cross sections. This is a real problem when attempting to determine defect densities from such measurements. Defect density values that could be proposed from modeling of the effective lifetime in the c-Si absorber ${ }^{[16-18]}$ have to assume values for the defect capture cross sections, which are not well known. The interpretation of experimental data is further complicated by the band bending and non-homogeneous distribution of carriers close to the heterointerface, which some authors express as field-effect passivation. This is particularly important in (p) a-Si:H/ (n) c-Si heterojunctions where the c-Si surface was shown to be strongly inverted. ${ }^{[19-27]}$

In order to get rid of the capture cross section influence, we propose to use techniques that only 
rely on equilibrium properties. In this letter, we use planar conductance measurements which are sensitive to the equilibrium band bending. We investigate a set of (p) a-Si:H/ (i) a-Si:H/ (n) c-Si heterostructures where the thickness of the intrinsic (i) a-Si:H layer is varied between 2 and $50 \mathrm{~nm}$. We demonstrate that the deep defect density, related to silicon dangling bonds, in the (i) a-Si:H layer is strongly increasing from $1 \times 10^{17}$ to $4 \times 10^{18} \mathrm{~cm}^{-3}$ when the (i) a-Si:H layer thickness is decreased from 50 to $2 \mathrm{~nm}$. We interpret this result in terms of defect formation and dependence of the defect density upon the position of the Fermi level with respect to the valence band edge. Quantitative analysis in the framework of the defect-pool model is discussed. The true knowledge of the density of state in such layer used as a passivation layer of the c-Si surface is decisive for a realistic modeling of the silicon based heterojunction solar cells.

\section{Experimental and modeling}

The heterojunction solar cells are based on a (n) c-Si consists of CZ wafers, $150 \mu \mathrm{m}$ thick, with nominal resistivity of $3 \Omega . \mathrm{cm}$. After cleaning the samples in a wet chemical HF bath the a-Si:H layers were processed using a $13.56 \mathrm{MHz}$ PECVD parallel-plate reactor at a temperature of $220^{\circ} \mathrm{C}$. Other deposition parameters are the same as in reference. ${ }^{[28]}$ On each sample, coplanar electrodes made of a stack of indium tin oxide (ITO) and silver with various inter-electrode distances had been deposited. The sketch of the studied structures is shown in Figure 1(a). These structures have been modeled using 2D TCAD simulator software (ATLAS from Silvaco $\left.{ }^{[29]}\right)$. The input parameters of the c-Si and a-Si:H layers can be found in the tables I and II in the Supporting Information part. The a-Si:H layers were modeled with a density of states (DOS) in the bandgap consisting of two exponential tail state distributions (acceptor-like for the conduction band tail and donor-like for the valence band tail) and two Gaussian deep defect distributions representative of dangling bonds (one donor-like centered at the energy EG,D with characteristic energy $\omega_{\mathrm{G}}=0.19 \mathrm{eV}$ and maximum density $\mathrm{N}_{\mathrm{G}}$ and one acceptor-like centered at 
$E_{G, A}=E_{G, D}+0.2 \mathrm{eV}$ with the same values of $\omega_{\mathrm{G}}$ and $\mathrm{N}_{\mathrm{G}}$, to account for the correlation energy of $0.2 \mathrm{eV}$ between the $\mathrm{D}^{+} / \mathrm{D}^{0}$ and $\mathrm{D}^{0} / \mathrm{D}^{-}$transitions). The position of these Gaussian distributions in both intrinsic and p-type a-Si:H, along with the correlation energy, have been chosen in agreement with typical values proposed in the Defect-Pool model. ${ }^{[30]}$ To account for the doping in (p) a-Si:H, an additional acceptor level was introduced in order to fix the Fermi level position at $0.39 \mathrm{eV}$ above the valence band, which corresponds to the activation energy of the conductance measured on test (p) a-Si:H layers deposited onto glass. In all structures the thickness of (p) a-Si:H was set to $10 \mathrm{~nm}$. The ohmic contacts were simulated by adjusting the workfunction value at the metal electrode at the same value as in (p) a-Si:H $(5.18 \mathrm{eV})$ with surface recombination velocities taken at $10^{6} \mathrm{~cm} / \mathrm{s}$ for both types of carriers. The band discontinuities at the heterointerface were taken at $0.40 \mathrm{eV}$ for the valence band and $0.18 \mathrm{eV}$ for the conduction band. ${ }^{[19]}$ No additional defects were taken into account at the interface. Indeed, since our heterostructures provide solar cells with open circuit values above $700 \mathrm{mV}$, the interface defect density is believed to be low enough to have negligible impact on the equilibrium band diagram and thus on the planar conductance. ${ }^{[31,32]}$ The equilibrium band diagram of the heterojunction calculated with $10 \mathrm{~nm}$ of buffer (i) a-Si:H is shown in Figure 1(b). We can notice the presence of the strong inversion layer at the heterointerface (here about $100 \mathrm{~nm}$ thick), which has been discussed previously in the literature (see for instance references [20-23]). In this band diagram, $\mathrm{V}_{\mathrm{bi}}^{(\mathrm{i}) \mathrm{a}-\mathrm{Si} \mathrm{H}}$ represents the electrostatic voltage drop in the (i) aSi:H layer. This increases when the thickness of the (i) a-Si:H layer increases, producing weaker inversion at the c-Si surface. 


\section{Results and discussion}

We measured the current-voltage characteristics, I-V, for each structure with a given (i) a-Si:H thickness, and for the three inter-electrode distances, $\mathrm{d}=0.5,1$, or $1.8 \mathrm{~mm}$. (see typical I-V curves for $\mathrm{d}=1.8 \mathrm{~mm}$ in the Supporting Information). These were found to be linear in the low voltage range $(|\mathrm{V}|<1 \mathrm{~V})$, allowing us to deduce the static conductance $\mathrm{G}=\mathrm{I} / \mathrm{V}$, and the normalized conductance $\mathrm{G}_{\text {norm }}=\mathrm{G} \times \mathrm{d} / \mathrm{L}$, where $\mathrm{L}$ is the length of the electrodes. Results obtained at room temperature are plotted (dots) in Figure 2(a) as a function of the thickness of the (i) a$\mathrm{Si}: \mathrm{H}$ buffer. Error bars correspond to the standard deviation of several measurements performed at different times and for the various inter-electrode distances. We notice that $\mathrm{G}_{\text {norm }}$ strongly decreases when the thickness of the (i) a-Si:H layer increases. This behavior is expected from the band bending in the structure. Indeed, in earlier work it was experimentally demonstrated that the conductance of such structure is determined by the surface inversion layer in c-Si. ${ }^{[20]}$ Thus, when the thickness of (i) a-Si:H increases the electrostatic potential drop $\mathbf{V}_{\mathbf{b i}}^{(\mathbf{i} \mathbf{a} \mathbf{a}-\mathbf{S i}: \mathbf{H}}$ in this layer increases, which implies a decrease of the potential drop in the c-Si and therefore a reduction of the hole inversion channel in $\mathrm{c}-\mathrm{Si}$.

The conductance values extracted from numerical modeling have also been plotted (black line) in Figure 2(a). With input parameters for the (i) a-Si:H layer commonly used for device grade (i) a-Si:H bulk material (see Supporting Information and references [33-37]), i.e. with low defect density $\left(\mathrm{N}_{\mathrm{G}}=3 \times 10^{15} \mathrm{~cm}^{-3} \cdot \mathrm{eV}^{-1}\right)$ and a characteristic valence band tail width $\mathrm{E}_{0, \mathrm{v}}$ of 43 meV, we observe that the variation with (i) a-Si:H thickness of simulated $\mathrm{G}_{\text {norm }}$ does not match that of the experimental results. The experimental decrease of conductance is much stronger than reproduced from the numerical calculations. Moreover, the simulation overestimates $\mathrm{G}_{\text {norm }}$ whatever the value of the (i) a-Si:H thickness, this overestimation being of three orders of 
magnitude for the thickest $(50 \mathrm{~nm})$ (i) a-Si:H layer. This means that the calculated hole concentration is too high at the c-Si surface, and that the calculated band bending in c-Si is too large. We have replaced the (i) a-Si:H layer by an ideal defect free insulator and found exactly the same $\mathrm{G}_{\text {norm }}$ curve. This means that the charge in the (i) a-Si:H with device grade parameters is too small to produce significant deviation from an ideal insulator and that the calculated potential drop $\mathbf{V}_{\mathbf{b i}}^{(\mathbf{i}) \mathbf{a}-\mathbf{S i : H}}$ is too small. In order to reproduce the experimental results, one needs to increase $\mathbf{V}_{\mathbf{b i}}^{(\mathbf{i}) \mathbf{a}-\mathbf{S i}: \mathbf{H}}$ so as to reduce the band bending in c-Si, which is only possible by increasing the defect density in (i) a-Si:H. Consequently, we model a new (i) a-Si:H layer, named in the following "proposed" layer, by increasing the value of the dangling bond concentration $\mathrm{N}_{\mathrm{DB}}$. We model the "proposed" layer by fixing the Gaussian deep defect distribution at the same energetic position as in the (p) a-Si:H layer $\left(\mathrm{E}_{\mathrm{G}, \mathrm{D}}=1250 \mathrm{meV}\right.$; $E_{G, A}=1450 \mathrm{meV}$ ). This is because the Fermi level in the (i) a-Si:H layer is much closer to the valence band than to the conduction band, so according to the Defect-Pool model the dangling bond distribution should peak at the same energy as in (p) a-Si:H. ${ }^{[30]}$ In the same way, the larger widths $\mathrm{E}_{0}$ of the tails distribution are taken identically to the $(\mathrm{p})$ a-Si:H layer $\left(\mathrm{E}_{0 \mathrm{v}}=60 \mathrm{meV}\right.$; $E_{0 c}=34 \mathrm{meV}$ ). The electrical parameters of the density of states in the "proposed" layer is shown in the Table II in Supporting Information. The simulation results are shown in Figure 2(a) as broken lines for "proposed" layers using various values of the dangling bond concentration $\mathrm{N}_{\mathrm{DB}}$, obtained by changing the value of the maximum of the Gaussian distributions $\mathrm{N}_{\mathrm{G}}$ $\left(\mathrm{NDB}_{\mathrm{DB}}=\mathrm{N}_{\mathrm{G}} \times \sqrt{\mathbf{2 \pi}} \times \omega_{\mathrm{G}}\right)$. As expected, we observe that the conductance values get smaller as $\mathrm{NDB}_{\mathrm{D}}$ is increased. However, it is also obvious that the experimental dependence of $G_{\text {norm }}$ upon (i) aSi:H thickness cannot be reproduced using a single $\mathrm{N}_{\mathrm{DB}}$ value, whatever this value, and that NDB has to be increased when the (i) a-Si:H thickness is decreased. The thickness dependent NDB values that allow reproducing the experimental $G_{\text {norm }}$ data are shown in Figure 2(b). NDB increases by a factor of $\sim 30$ when the (i) a-Si:H thickness decreases from 50 to $2 \mathrm{~nm}$. Note that 
if we keep the value of the valence band tail width at $43 \mathrm{meV}$ as in device quality bulk, the results are very close to those obtained for $60 \mathrm{meV}$. However, if we keep the defect state parameters of "bulk" material, NDB has to be significantly larger especially for the thicker (i) a$\mathrm{Si}: \mathrm{H}$, and it only increases by a factor of $\sim 10$ when the (i) a-Si:H thickness decreases from 50 to $2 \mathrm{~nm}$ (dot symbols in Figure 2(b)).

The increase of $\mathrm{N}_{\mathrm{DB}}$ with decreasing (i) a-Si:H thickness is compatible with the equilibration of defects in the Defect-Pool model. Indeed, this model predicts that the dangling bond defect density increases when the Fermi level is pushed closer to the valence band edge, which is precisely the case when the (i) a-Si:H layer gets thinner. In order to make a more quantitative comparison, we need to know the position of the Fermi level in the (i) a-Si:H layer, so we have studied the bend bending at the heterointerface of our samples and determined $\left(E_{F}-E_{v}\right)$ int, the difference between the Fermi level position and the valence band of c-Si at the (i) a-Si:H/c-Si interface. We have used two ways. Firstly, assuming that the planar conductance is only due to the holes in the inverted surface region of c-Si, we used a preceding analytical calculation that directly relates $G_{n o r m}$ to $\left(E_{F}-E_{v}\right)$ int. ${ }^{[32]}$ Secondly, we used the full $2 D$ numerical calculation of the current as a function of applied bias without any assumption, and, for each calculated result of $G_{\text {norm }}$ reported in Figure 2(a) we noted the value of $\left(E_{F}-E_{v}\right)$ int. Figure 3 shows the results of both approaches, presenting $G_{\text {norm }}$ as a function of $\left(E_{F}-E_{v}\right)$ int. The open circle symbols correspond to the simulation performed for both different (i) a-Si:H thicknesses and NDB values, in order to cover a large energy range, while the black solid line is the curve of the 1D analytical calculation assuming that the conductance is only due to the transport of holes in the c-Si wafer. We observe a perfect agreement between our 2D simulations and the 1D analytical model, which proves that the coplanar conductance is indeed determined by the lateral hole current at the c-Si surface due to the inversion layer. 
Figure 3 is interesting since it allows us to determine the position of the Fermi level at the

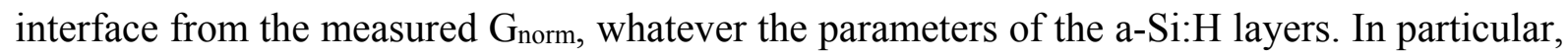
for each (i) a-Si:H thickness of our samples, we can extract the value of $\left(E_{F}-E_{v}\right)$ int. On the other hand, the Defect-Pool model allows to compute the integrated dangling bond density as a function of $\left(E_{F}-E_{v}\right)$ in a-Si:H. When the Fermi level lies well below midgap, the model predicts an exponential dependence of $\mathrm{NDB}_{\mathrm{DB}}{ }^{[30]}$ which is depicted in Figure $\mathbf{4}$ for several values of the width of the valence band tail, $\mathrm{E}_{0, \mathrm{v}}$. We can then compare the values of $\mathrm{N}_{\mathrm{DB}}$ extracted experimentally from our conductance measurements to the values suggested by the defect-pool model, when we change the (i) a-Si:H thickness. To this purpose, we have added in Figure 4 the values extracted experimentally for each (i) a-Si:H layer thickness, and we attached to this value an interval of $\left(E_{F}-E_{v}\right)$ corresponding to the values observed in the $2 \mathrm{D}$ calculation in the (i) a-Si:H layer when going from the (p) a-Si:H / (i) a-Si:H interface to the (i) a-Si:H / (n) c-Si one.

Obviously, for the thinnest (i) a-Si:H layers of 2 to $5 \mathrm{~nm}$, the dangling bond density predicted by the Defect-Pool model is compatible with the experimentally extracted value only for a valence band tail width larger than $65 \mathrm{meV}$, which is significantly larger than for device grade "bulk" (i) a-Si:H, where the lowest values are around $42 \mathrm{meV} \cdot{ }^{[38]}$ Conversely, for the thicker (i) a-Si:H layer of $50 \mathrm{~nm}$, the value of the valence band tail width cannot be larger than $50 \mathrm{meV}$, meaning that with such thickness the deposited material is equivalent to that of device grade thick "bulk" material. ${ }^{[38]}$ It is worth mentioning that an increase of the valence band tail width when the (i) a-Si:H thickness decreases below $10 \mathrm{~nm}$ was also suggested from the modeling of the effective lifetime in these structures, assuming that interface defects responsible for 
recombination of carriers photogenerated in c-Si can be considered as an extension of the DOS in (i) a-Si:H. ${ }^{[39]}$

In conclusion, we have shown that the static planar conductance of (p) a-Si:H / (i) a-Si:H / (n) c-Si structures is very useful since it does not depend on recombination parameters like capture cross sections, and it allows one to obtain a clear picture of the band bending at the heterojunction. A detailed analysis from both $1 \mathrm{D}$ analytical and 2D full numerical calculations was used to determine the evolution of the deep defect density $\mathrm{NDB}_{\mathrm{DB}}$ (i) a-Si:H as a function of the layer thickness. When the (i) a-Si:H thickness is decreased from $50 \mathrm{~nm}$ to $2 \mathrm{~nm}$, we measured an increase of a factor of $\sim 30$ of $\mathrm{N}_{\mathrm{DB}}$. While an increase of $\mathrm{N}_{\mathrm{DB}}$ can be fairly understood and is expected in the frame of the Defect-Pool model the magnitude of this increase shows that the width of the valence band tail cannot be considered as independent of the (i) a$\mathrm{Si}: \mathrm{H}$ layer thickness. Instead, while our results for an (i) a-Si:H thickness of $50 \mathrm{~nm}$ are compatible with a value of $\sim 45-50 \mathrm{meV}$ typical of "bulk" device grade (i) a-Si:H, we find that this significantly increases for thicknesses below $10 \mathrm{~nm}$ which may be related to an increased disorder in such thin layers. Our results shed some new light on the density of defects in the buffer (i) a-Si:H layer in silicon heterojunction structures. The observed increase of both the dangling bond density and the valence band tail width when decreasing the buffer layer thickness could be related to a higher density of interface states and to lower passivation properties of the silicon surface (as is known from experiments). Therefore, further work should concentrate on the determination of interface defect densities and on the link to the DOS in (i) a-Si:H. 


\section{Supporting Information}

See Supporting Information for the graph of the experimental coplanar current-tension characteristics for various (i) a-Si:H thickness and for the tables containing input electrical parameters used for the modeling of the c-Si:H and a-Si:H layers.

\section{Acknowledgments}

The authors gratefully thank Delfina Muñoz, Tristan Carrere and Wilfried Favre from CEAINES for the elaboration of the samples.

Received: ((will be filled in by the editorial staff))

Revised: ((will be filled in by the editorial staff)) Published online: ((will be filled in by the editorial staff))

\section{References}

[1] K. Yoshikawa, H. Kawasaki, W. Yoshida, T. Irie, K. Konishi, K. Nakano, T. Uto, D. Adachi, M. Kanematsu, H. Uzu, K. Yamamoto, Nature Energy 2017, 2, 17032.

[2] M. A. Green, Y. Hishikawa, E. D. Dunlop, D. H. Levi, J. Hohl-Ebinger, M. Yoshita, A. W. Y. Ho-Baillie, Prog. Photovol. Res. Appl. 2019, 27, 3.

[3] Y. Tsunomura, Y. Yoshimine, M. Taguchi, T. Baba, T. Kinoshita, H. Kanno, H. Sakata, E. Maruyama, M. Tanaka, Sol. Energy Mater. Sol. Cells 2009, 93, 670.

[4] S. Martin de Nicolas, J. Coignus, W. Favre J.-P. Kleider, D. Muñoz, Sol. Energy Mater. Sol. Cells 2013, 115, 129-137.

[5] U. K. Das, M. Z. Burrows, M. Lu, S. Bowden, R. W. Birkmire, Appl. Phys. Lett. 2008, 92, 063504.

[6] A. Descoeudres, L. Barraud, S. De Wolf, B. Strahm, D. Lachenal, C. Guérin, Z. C. Holman, F. Zicarelli, B. Demaurex, J. Seif, J. Holovsky, C. Ballif, Appl. Phys. Lett. 2011, 91, 123506.

[7] J. Ge, Z. P. Ling, J. Wong, T. Mueller, A. G. Aberle, Energy Procedia 2012, 15, 107. 
[8] M. R. Page, Q. Wang, T. H. Wang, Y. Yan, S. W. Johnston, T. F. Ciszek, 13th Workshop on Crystalline Silicon Solar Cell Materials and Processes, Vail, Colorado 2003, p. 194.

[9] M. R. Page, E. Iwaniczko, Y. Xu, Q. Wang, Y. Yan, L. Roybal, H. M. Branz, T. H. Wang, IEEE 4th World Conference on Photovoltaic Energy Conversion (WCPEC-4), Waikoloa, Hawaii 2006, p. 1485.

[10] J.-C. Hsiao, C.-H. Chen, C.-C. Lin, D.-C. Wu, P. Yu, J. Electrochem. Soc. 2011, 158 H876.

[11] S. De Wolf, M. Kondo, Appl. Phys. Lett. 2007, 90, 042111.

[12] J. W. A. Schüttauf, C. H. M. van der Werf, I. M. Kielen, W. G. J. H. M. van Sark, J. K. Rath, R. E. I. Schropp, Appl. Phys. Lett. 2011, 98, 153514.

[13] J. W. A. Schüttauf, C.H.M. van der Werf, I.M. Kielen, W.G.J.H.M. van Sark, J.K. Rath, R.E.I. Schropp, J. Non-Cryst. Solids, 2012, 358, 2245.

[14] H. Meddeb, T. Bearda, Y. Abdelraheem, H. Ezzaouia, I. Gordon, J. Szlufcik J. Poortmans, J. Phys. D: Appl. Phys. 2015, 48, 415301.

[15] F. Meng, L. Shen, J. Shu, L. Zhang, J. Liu, Y. Liu, Z. Liu, Appl. Phys. Lett. 2015, 107, 223901.

[16] C. Leendertz, R. Stangl, T. F. Schulze, M. Schmidt, L. Korte, Phys. Status Solidi C 2010, 7, 1005 .

[17] C. Leendertz, N. Mingirulli, T. F. Schulze, J.-P. Kleider, B. Rech, L. Korte, Appl. Phys. Lett. 2011, 98, 202108.

[18] D. Reaux, J. Alvarez, M.-E. Gueunier-Farret, J.-P. Kleider, Energy Procedia 2015, 77, 153.

[19] J.-P. Kleider, A. S. Gudovskikh, P. Roca i Cabarrocas, Appl. Phys. Lett. 2008, 92, 162101. [20] J.-P. Kleider, Y. M. Soro, R. Chouffot, A. S. Gudovskikh, P. Roca i Cabarrocas, J. DamonLacoste, D. Eon, P. -J. Ribeyron, J. Non-Cryst. Solids, 2008, 354, 2641.

[21] O. A. Maslova, J. Alvarez, E. V. Gushina, W. Favre, M.-E. Gueunier-Farret, A. S. Gudovskikh, A. V. Ankudinov, E. I. Terukov, J.-P. Kleider, Appl. Phys. Lett. 2010, 97, 252110 .

[22] M. Filipič, Z. C. Holman, F. Smole, S. de Wolf, C. Ballif, M. Topič, J. Appl. Phys. 2013, 113, 074504.

[23] M. Ghannam, G. Shehadah, Y. Abdulraheem, J. Poortmans, Sol. Energy Mater. Sol. Cells 2015, 132, 320.

[24] W. Favre, M. Labrune, F. Dadouche, A. S. Gudovskikh, P. Roca i Cabarrocas, J. P. Kleider, Phys. Status Solidi C 2010, 7, 1037.

[25] K. Ghosh, C. J. Tracy, S. Herasimenka, C. Honsberg, S. Bowden, 35th IEEE Photovoltaic Specialists Conference, Honolulu, HI 2010, p. 001383.

[26] J. V. Li, R. S. Crandall, D. L. Young, M. R. Page, E. Iwaniczko, Q. Wang, J. Appl. Phys. 2011, 110, 114502.

[27] O. Maslova, A. Brézard-Oudot, M. E. Gueunier-Farret, J. Alvarez, W. Favre, D. Muñoz, J. P. Kleider, Appl. Phys. Lett. 2013, 103, 183907.

[28] D. Muñoz, T. Desrues, A.-S. Ozanne, N. Nguyen, S. de Vecchi, F. Souche, S. Martin de Nicolàs, C. Denis, P.-.J. Ribeyron, Proceedings of the 26th European Photovoltaic Solar Energy Conference and Exhibition, Hamburg, Germany 2011, p. 861-864.

[29] User's manual for ATLAS from Silvaco International (Silvaco Inc. Santa Clara, 2016)

[30] M. J. Powell, S. C. Deane, Phys. Rev. B 1996, 53, 10121.

[31] M. Schmidt, H. Angermann, E. Conrard, L Korte, A Laades, K. V. Maydell, C. Schubert, R. Stangl, IEEE 4th World Conf. on Photovoltaic. Energy Conf. 2006, p. 1433-1438.

[32] R. Varache, J. P. Kleider, W. Favre, L. Korte, J. Appl.Phys. 2012, 112, 123717.

[33] A. Levtchenko, S. Le Gall, R. Lachaume, J. Michalon, S. Collin, J. Alvarez, Z. Djebbour, J.-P. Kleider, Nanotech. 2018, 29, 255401. 
[34] A. Levtchenko, S. Le Gall, R. Lachaume, J. Michalon, S. Collin, J. Alvarez, Z. Djebbour, J.-P. Kleider, Phys. Status Solidi C 2017, 14, 1700181.

[35] Y. Hayashi, D. Li, A. Ogura, Y. Ohshita, IEEE J. Photov. 2013, 3, 1149.

[36] M. Rahmouni, A. Datta, P. Chatterjee, J. Damon-Lacoste, C. Ballif, P. Roca i Cabarrocas, J. Appl.Phys. 2010, 107, 054521.

[37] A. Fantoni, M. Viera, R. Martins, Sol. Energy Mater. Sol. Cells 2002, 73, 151-162.

[38] M. Vanecek, B.P. Nelson, A.H. Mahan, R.S. Crandall, J. Non-Cryst. Solids 1991, 137\&138, 191.

[39] J.-P. Kleider, J. Alvarez, R. Brüggemann, M.-E Gueunier-Farret, Phys. Status Solidi A 2019, 1800877. 
(a)

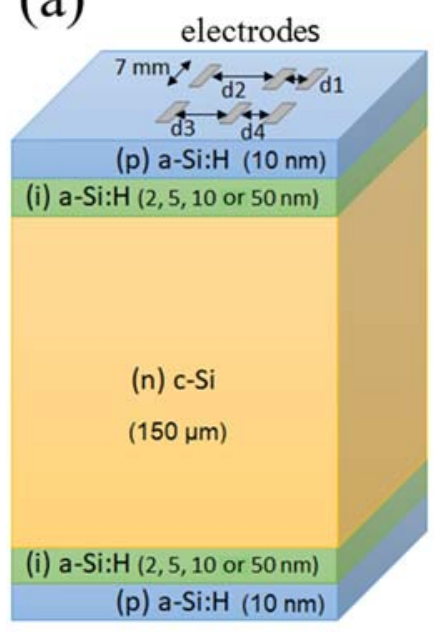

(b)

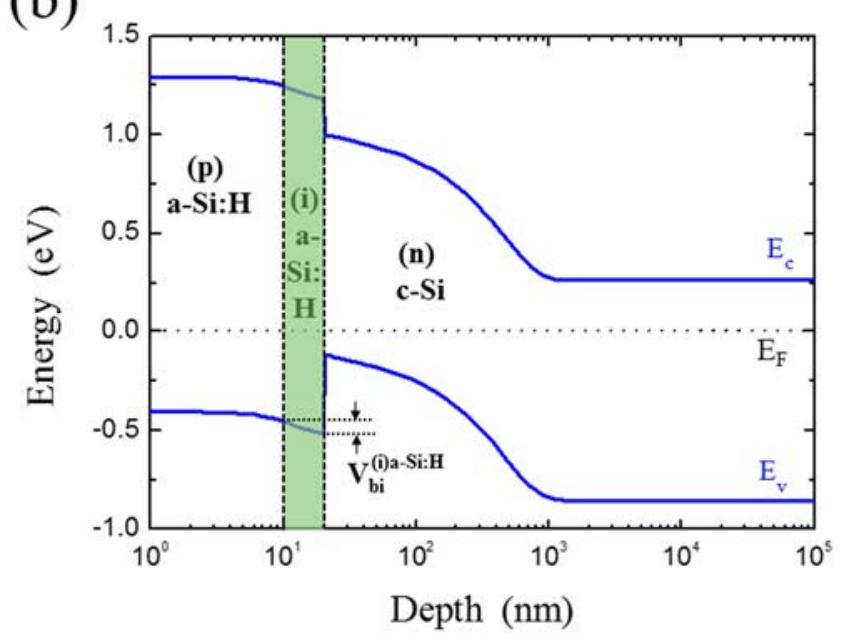

Figure 1. (a) Sketch of the solar cell studied here. The various inter-electrode distances are $\mathrm{d} 1=1.8 \mathrm{~mm}, \mathrm{~d} 2=6.5 \mathrm{~mm}, \mathrm{~d} 3=5 \mathrm{~mm}, \mathrm{~d} 4=3.15 \mathrm{~mm}$. (b) Equilibrium band diagram of the structure calculated with $10 \mathrm{~nm}$ of (i) a-Si:H ( $\mathrm{E}_{\mathrm{c}}$ : conduction band energy, $\mathrm{E}_{\mathrm{v}}$ : valence band and $\mathrm{EF}_{\mathrm{F}}$ : Femi level). $\mathrm{V}_{\mathrm{bi}}{ }^{(\mathrm{i}) \mathrm{a}-\mathrm{Si}: \mathrm{H}}$ is the potential drop in the (i) a-Si:H layer. Note the logarithmic scale for the depth, referred to the top surface. 
(a)

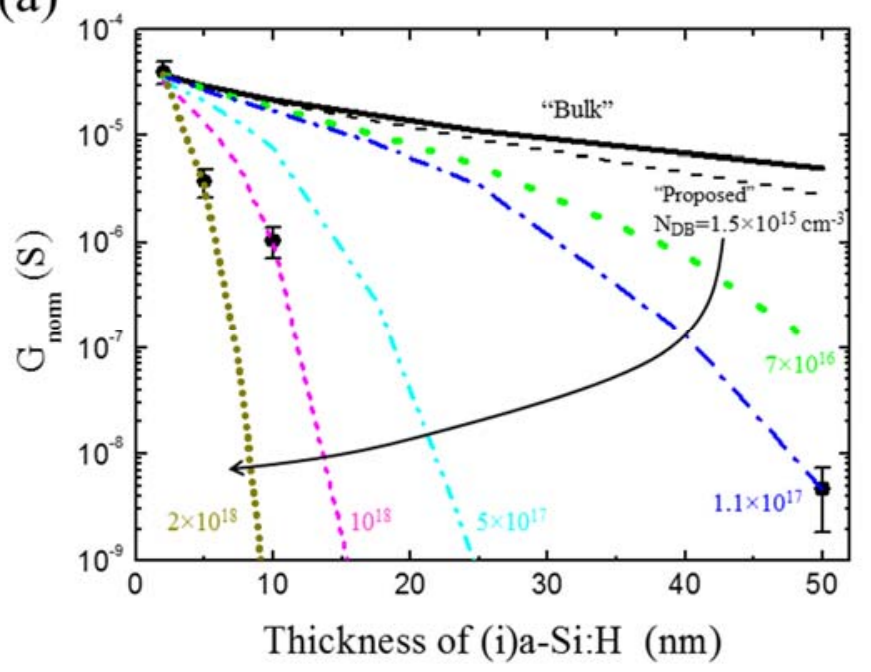

(b)

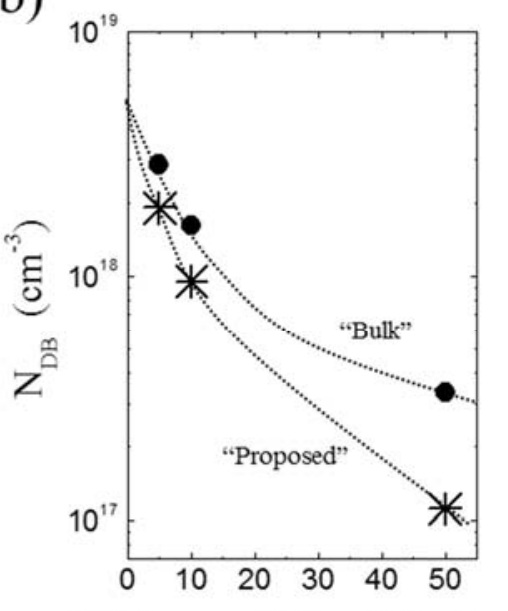

Thickness of (i)a-Si:H (nm)

Figure 2. (a) Variation of the normalized conductance $\mathrm{G}_{\text {norm }}$ as a function of the thickness of (i) a-Si:H layer done at room temperature. The Experimental data (dots) are compared to simulations (line and broken lines). The black line corresponds to the simulated results with (i) aSi:H ("bulk") modeled with input parameters commonly used for bulk material whereas the broken lines correspond to various simulations with input parameters of the new (i) a-Si:H buffer layer ("proposed") by changing the $\mathrm{N}_{\mathrm{DB}}$ values (black: $1.5 \times 10^{15}$, green: $7 \times 10^{16}$, blue: $1.1 \times 10^{17}$, cyan: $5 \times 10^{17}$, magenta: $1 \times 10^{18}$, dark yellow: $\left.2 \times 10^{18} \mathrm{~cm}^{-3}\right)$. (b) Effective defect state $\mathrm{NDB}$ as a function of the (i) a-Si:H thickness for two values of tails energy width parameters corresponding to (i) a-Si:H “proposed" layer (crosses: $\mathrm{E}_{0, \mathrm{v}}=60 \mathrm{meV}$ ) and (i) a-Si:H "bulk" (dots: $\mathrm{E}_{0, \mathrm{v}}=43 \mathrm{meV}$ ). The results for the "proposed" layer (crosses) are extracted from Figure 2(a). The dotted lines are a guide for eyes. 


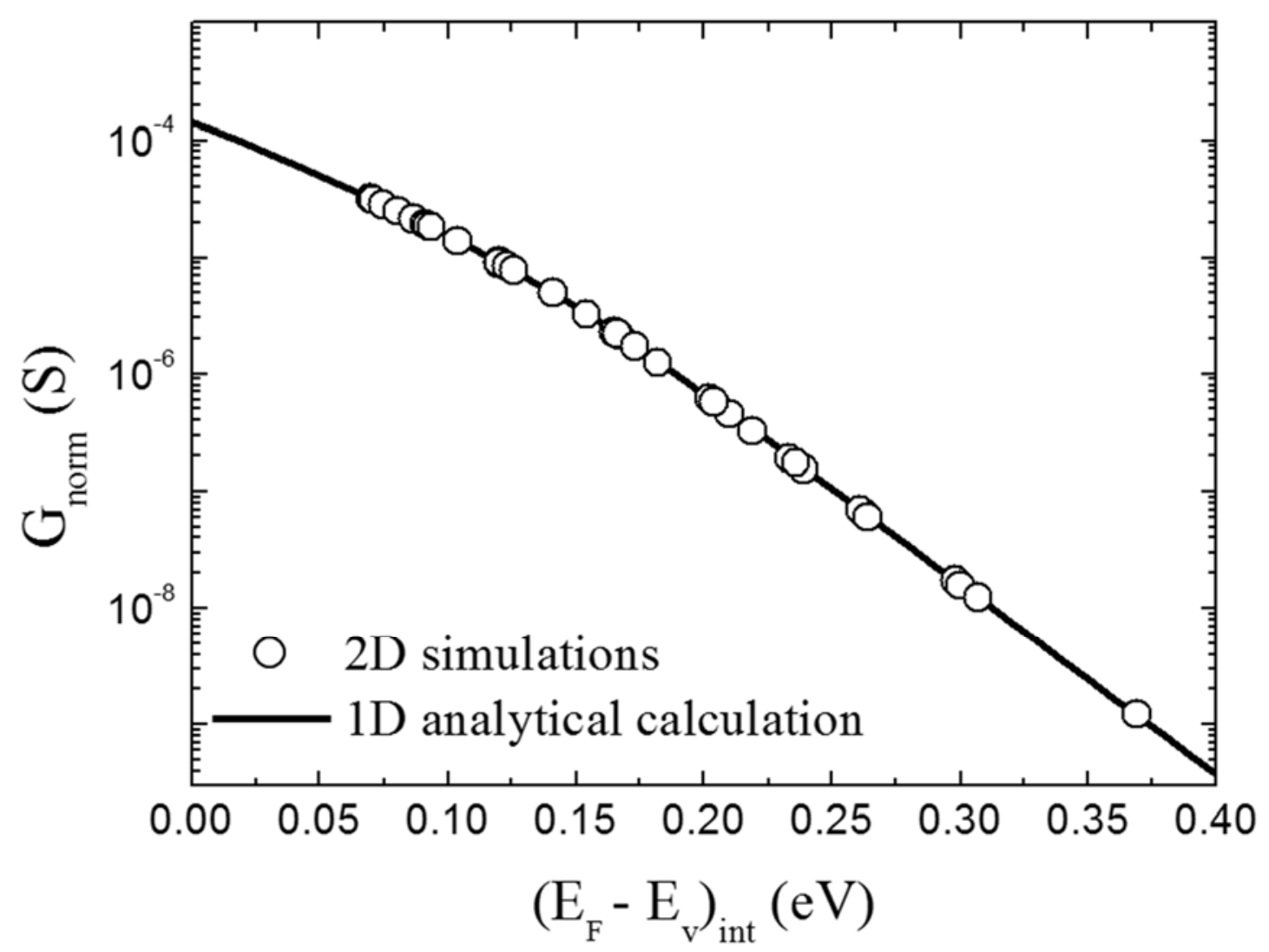

Figure 3. Variation of the normalized conductance $G_{n o r m}$ as a function of $\left(E_{F}-E_{v}\right)$ int. The black line represents the 1D analytical calculation from the approach of reference [32], the black open circles are the values extracted from 2D simulations for various values of both (i) a-Si:H thickness and $\mathrm{N}_{\mathrm{DB}}$. 


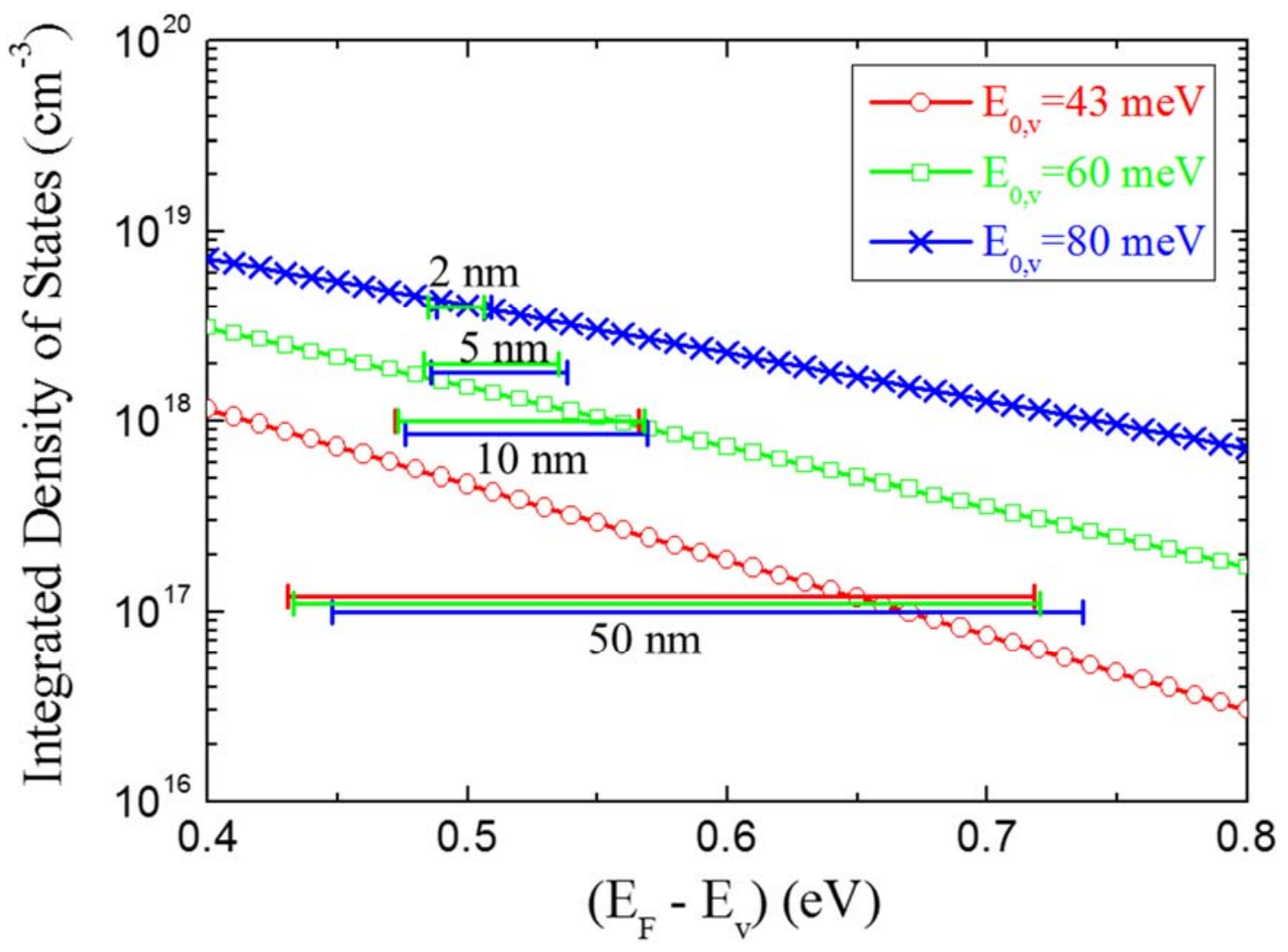

Figure 4. Dependence of the dangling bond density on the Fermi level position calculated using the Defect-Pool model with the parameters of reference [30] and for three values of the valence band tail width: $\mathrm{E}_{0, \mathrm{v}}=45 \mathrm{meV}$ (red open circles), $\mathrm{E}_{0, \mathrm{v}}=65 \mathrm{meV}$ (green open squares) and $\mathrm{E}_{0, \mathrm{v}}=85$ meV (blue crosses). Calculations were performed at the equilibration temperature of $500 \mathrm{~K}$, using the temperature dependence of $\mathrm{E}_{0, \mathrm{v}}:\left(\mathrm{E}_{0, \mathrm{v}}(\mathrm{T})\right)^{2}=\left(\mathrm{E}_{0, \mathrm{v}} \mathrm{T}=0\right)^{2}+(\mathrm{kT})^{2}$. Also indicated are the experimental $N_{D B}$ values extracted from our conductance measurements for the four (i) aSi:H thicknesses, with the corresponding intervals of $\left(E_{F}-E_{v}\right)$ that reflect the band bending at $500 \mathrm{~K}$ in the (i) a-Si:H layer when going from the (p) a-Si:H / (i) a-Si:H interface to the (i) a$\mathrm{Si}: \mathrm{H} /(\mathrm{n}) \mathrm{c}-\mathrm{Si}$ one. The colour of the intervals corresponds to the $\mathrm{E}_{0, \mathrm{v}}$ values ones displayed in the legend. 